\title{
Effect of solidification parameters on the secondary dendrite arm spacing in MAR M-247 superalloy determined by a novel approach
}

\author{
S. Milenkovic ${ }^{1, \text { a }}$, M. Rahimian ${ }^{1}$, I. Sabirov ${ }^{1}$, and L. Maestro ${ }^{2}$ \\ ${ }^{1}$ IMDEA Materials Institute, C/ Eric Kandel 2, 28906 Getafe, Madrid, Spain \\ 2 Precicast Bilbao, S.A. El Barracón 1, 48901 Barakaldo (Bizkaia), Spain
}

\begin{abstract}
The effect of solidification parameters on the secondary dendrite arm spacing in a MAR-M247 Nibased superalloy has been studied by a novel approach, based on physical simulation of melting/solidification experiment with a constant cooling rate and variable temperature gradient. The applied experimental method proved to be efficient as it yielded a spread of microstructures corresponding to a range of well controlled solidification rates in a single melting/solidification experiment. In addition, it has been demonstrated that secondary dendrite arm spacing is better related to the solidification rate than to the cooling rate in the case when significant variations of thermal parameters during the solidification process occur.
\end{abstract}

\section{Introduction}

Ni-based superalloys encompass complex alloy systems and have been widely used in advanced aircraft engines due to increased high-temperature strength and oxidation resistance $[1,2]$. Fundamental studies have investigated the effect of solidification parameters on the microstructure of Ni-based superalloys [3]. Among various microstructural characteristics, primary dendrite arm spacing (PDAS) $\lambda_{1}$ and secondary dendrite arm spacing (SDAS) $\lambda_{2}$ have a strong effect on the mechanical properties of these materials [4]. It was reported that both PDAS and SDAS are determined by processing parameters such as thermal gradient $(\boldsymbol{G})$ and solidification rate $(\boldsymbol{V})$ [5]. Numerous studies have been carried out to investigate the effect of the processing parameters on SDAS [1,3,5-8]. However, directional solidification methods such as the Bridgman method [1,6,7] and the liquid metal cooling (LMC) technique [8] were used in these studies where solidification rate and thermal gradient are maintained constant during the solidification process. There are many parts in aero engines which are produced by investment casting and exhibit a polycrystalline microstructure [9]. For these castings both parameters can significantly vary during solidification in different areas of the casting. In this study, a novel approach was used to study a relationship between the solidification process parameters (temperature gradient, cooling rate, and solidification rate) and SDAS in the MAR-M247 Ni-based superalloy. It is based on a physical simulation of the casting process and is characterized by high efficiency and minimum number of samples required to study the relationship.

\footnotetext{
${ }^{a}$ Corresponding author: srdjan.milenkovic@imdea.org
}

\section{Experimental procedure}

The MAR-M247 Ni-based superalloy was supplied by Precicast Bilbao (Spain). Chemical composition of the material, provided by the supplier, was (wt.\%): $\mathrm{C}=0.15$, $\mathrm{Cr}=8.0, \mathrm{Mo}=0.6, \mathrm{Ti}=1.0, \mathrm{Co}=10.0, \mathrm{~W}=10.0, \mathrm{Ta}=3.0$, $\mathrm{Al}=5.5, \mathrm{Hf}=1.5, \mathrm{~B}=0.015, \mathrm{Zr}=0.03$. Specimens with a diameter of $10 \mathrm{~mm}$ and a length of $121.5 \mathrm{~mm}$ were machined from the ingots. A thermocouple (R-type) was welded to the midsection of each sample (marked as TC4 on Fig. 1) to control the temperature during melting/solidification experiments. R-type thermocouples were also welded at 4,8 , and $12 \mathrm{~mm}$ distance from the midsection of the sample to record the temperature distribution along the sample axis during the experiment. In Fig. 1, these thermocouples are marked as TC3, TC2, and $\mathrm{TC} 1$, respectively. A quartz tube with the slot of $3.2 \mathrm{~mm}$ was used to contain the liquid metal zone and the thermocouples were placed in the slot. Thermocouples were fixed to the surface of the quartz tube by cement. Melting/solidification experiments were carried out in the argon atmosphere using a GLEEBLE 3800 thermomechanical simulator. The samples were heated at a rate of $40^{\circ} \mathrm{C} / \mathrm{s}$ to $1240^{\circ} \mathrm{C}$. Then, the heating rate was decreased to $2{ }^{\circ} \mathrm{C} / \mathrm{s}$ in the temperature range of $1240-1320^{\circ} \mathrm{C}$. After the temperature reached $1320^{\circ} \mathrm{C}$, it was manually increased very slowly up to $\sim 1355^{\circ} \mathrm{C}$ until the clear evidence of melting appeared.

Then, the heating process was stopped, the samples were kept at this temperature for $100 \mathrm{~s}$ and thereafter cooled down by $100^{\circ} \mathrm{C}$ at two different cooling rates of 0.25 and $10^{\circ} \mathrm{C} / \mathrm{s}$. The selected cooling rates are in the relevant range of the cooling rates during investment casting of nozzle guide vanes from this Ni-based superalloy [10]. It should be noted that despite some temperature gradient along the radius of the sample 


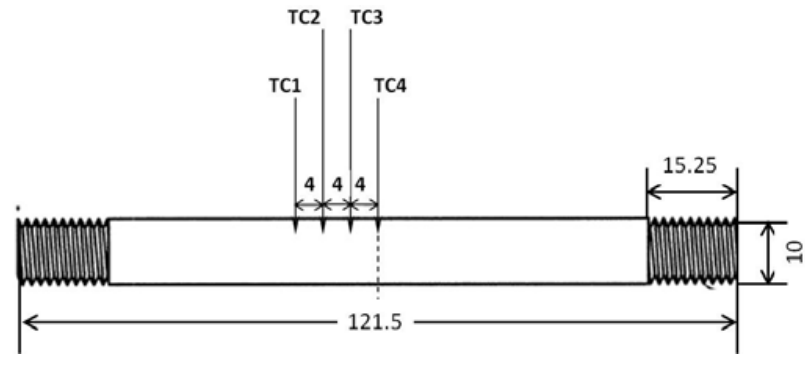

Figure 1. A schematic presentation of the sample with 4 welded thermocouples. All dimensions are in $\mathrm{mm}$.

$\left(\sim 30^{\circ} \mathrm{C}\right)$, the cooling rate of the surface and centre is the same. The samples were compressed in a stroke controlled manner during cooling in order to suppress formation of shrinkage porosity and to compensate thermal contraction. At least two samples were tested for each condition and the results were found to be reproducible. Two types of copper grips with different geometrical shapes were used for experiments. Partial contact copper grips having a contact length of $12 \mathrm{~mm}$ with the samples were used for experiments with the set cooling rate of $0.25^{\circ} \mathrm{C} / \mathrm{s}$. Full contact copper grips having a contact length of $30.5 \mathrm{~mm}$ with the samples were used for the experiments with set cooling rate of $10^{\circ} \mathrm{C} / \mathrm{s}$ [11].

The melted/solidified sections were cut out from the tested samples. From these sections, specimens for microstructural characterization were prepared using standard metallographic techniques. To reveal the dendritic microstructure, the specimens were etched using a chemical solution consisting of $25 \mathrm{~g} \mathrm{FeCl}_{3}, 60 \mathrm{ml}$ $\mathrm{HCl}$, and $25 \mathrm{ml} \mathrm{H}_{2} \mathrm{O}$. The temperature-controlled areas of these specimens (areas under welded thermocouples) were studied using optical microscope OLYMPUS BX51. The quantitative analysis of dendritic microstructure was performed using ANALYSIS software. The measurement of SDAS was done by counting the number of secondary arms over a length on at least five well defined trunks.

\section{Results and discussion}

The temperature-time plots recorded during solidification at nominal cooling rates of 0.25 and $10^{\circ} \mathrm{C} / \mathrm{s}$ are shown in Figs. $2 \mathrm{a}$ and $\mathrm{b}$, respectively. It should be noted that the data from the thermocouple TC1 are not presented since the temperature were below the solidus temperature. The linear character of the plots shows that the cooling rate was very well controlled. Thus, from these plots, the true cooling rate during solidification $R=d T / d t$ can be easily estimated for each area with the spot welded thermocouple.

It is reported that solidification occurs in the temperature range of $1280-1350{ }^{\circ} \mathrm{C}$ [12]. Data on true cooling rate at different thermocouple locations for samples solidified at both set cooling rates are listed in Table 1. One can observe that the true cooling rate tends to increase slightly with distance from the midsection.

The same data were used to plot the temperature variation along the axis of the sample, as shown in
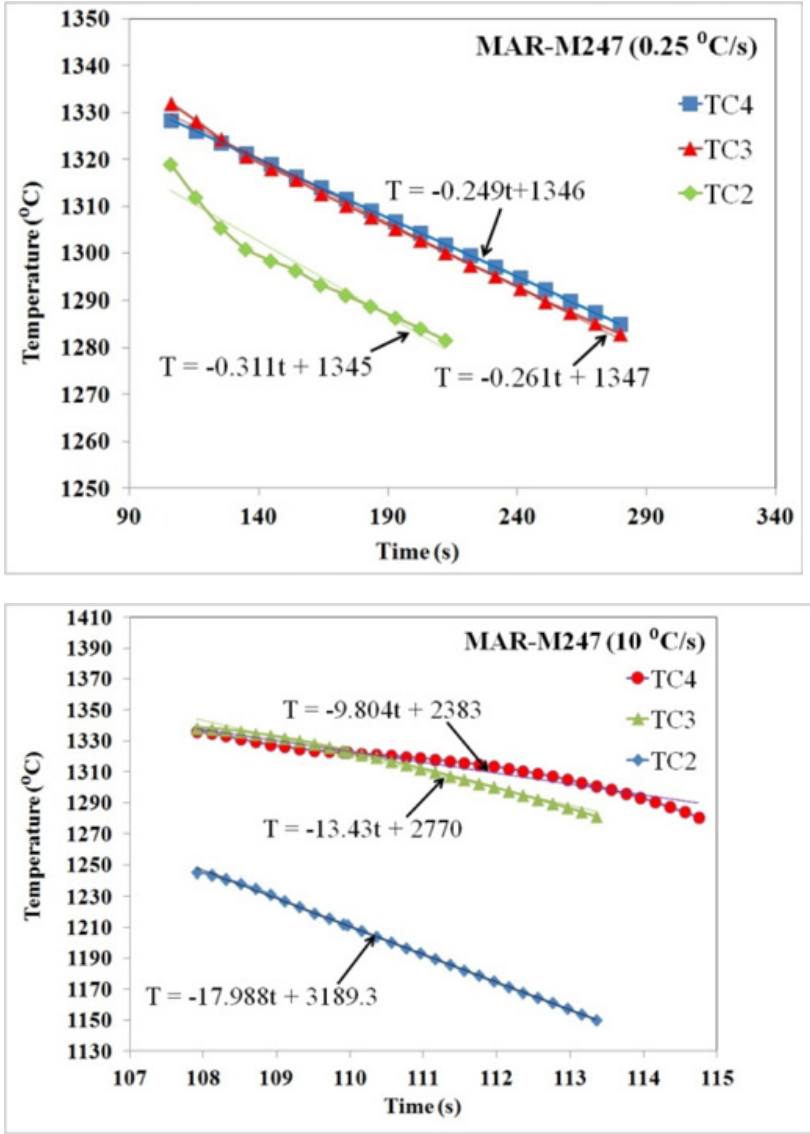

Figure 2. Temperature - time plots recorded by different thermocouples during solidification at cooling rates of: a) $0.25^{\circ} \mathrm{C} / \mathrm{s}$ and b) $10^{\circ} \mathrm{C} / \mathrm{s}$.

Fig. 3. It is assumed that the distribution of temperature along the specimen axis is symmetrical with respect to the midsection [13]. It is seen that the temperature decreases with increasing distance from midsection. Also, the temperature profile at the set cooling rate of $10^{\circ} \mathrm{C} / \mathrm{s}$ (Fig. 3b) is much steeper compared to that at the set cooling rate of $0.25^{\circ} \mathrm{C} / \mathrm{s}$ (Fig. 3a) due to different geometries of copper grips providing different thermal diffusivity during heating/cooling [13].

The obtained $\boldsymbol{T}-\boldsymbol{x}$ plots can be described by a polynomial function

$$
T=a x^{2}+b x+c
$$

as shown in Figs. 3a,b and the constants $\boldsymbol{a}, \boldsymbol{b}$ and $\boldsymbol{c}$ can be easily determined. These data are listed in Table 2 . The derivative of this quadratic function describes thermal gradient $\boldsymbol{G}$ along the sample axis

$$
G=d T / d x=2 a x+b .
$$

Thus, temperature gradient can be easily estimated from these $\boldsymbol{T}-\boldsymbol{x}$ plots for any point along the sample axis using data from Table 2.

Figures $3 \mathrm{c}$ and $\mathrm{d}$ illustrate the distribution of the thermal gradient along the axis in both samples. It should be noted that the $\boldsymbol{G}$ - values in the midsection $(x=0)$ were 
Table 1. Data on thermal gradient, true cooling rate and solidification rate in studied areas of the samples.

\begin{tabular}{|l|l|l|l|l|l|l|}
\hline \multirow{3}{*}{$\begin{array}{l}\text { Distance } \\
{[\mathrm{mm}]}\end{array}$} & \multicolumn{5}{|c|}{$0.25^{\circ} \mathrm{C} / \mathrm{s}$ set cooling rate } \\
\cline { 2 - 7 } & $R$ & $G$ & $v$ & $R$ & $G$ & $v$ \\
& $\left.\left[{ }^{\circ} \mathrm{C} / \mathrm{s}\right)\right]$ & {$\left[{ }^{\circ} \mathrm{C} / \mathrm{mm}\right]$} & {$[\mu \mathrm{m} / \mathrm{s}]$} & $\begin{array}{l}\left.{ }^{\circ} \mathrm{C} / \mathrm{s}\right] \\
{\left[{ }^{\circ} \mathrm{C} / \mathrm{mm}\right]}\end{array}$ & {$[\mu \mathrm{m} / \mathrm{s}]$} \\
\hline 0 & 0.25 & 1 & 250 & 9.8 & 1 & 9800 \\
\hline 4 & 0.27 & 3.13 & 83 & 13.43 & 16.83 & 790 \\
\hline 8 & 0.31 & 4.27 & 73 & 17.99 & 33.66 & Not melted \\
\hline
\end{tabular}

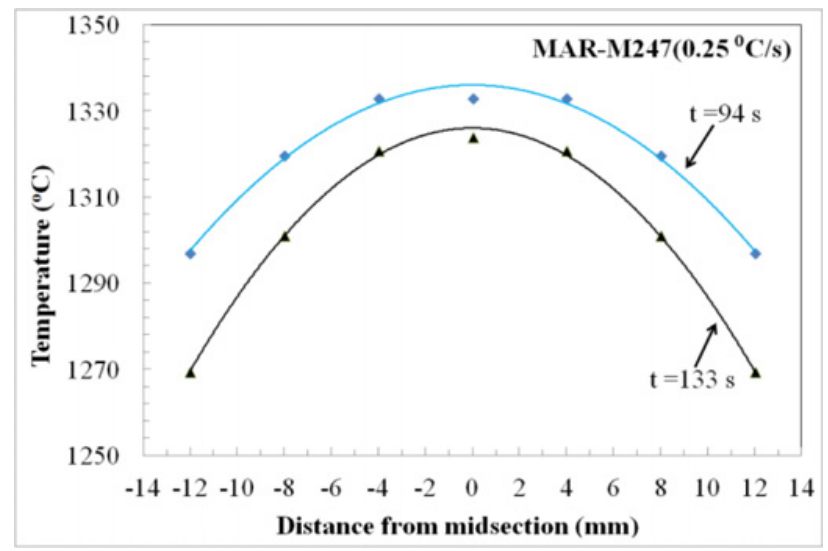

(a)

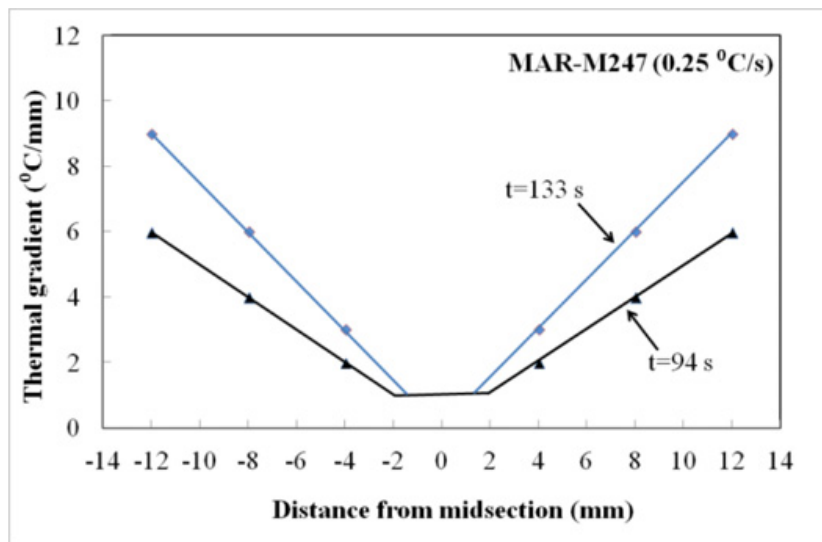

(c)

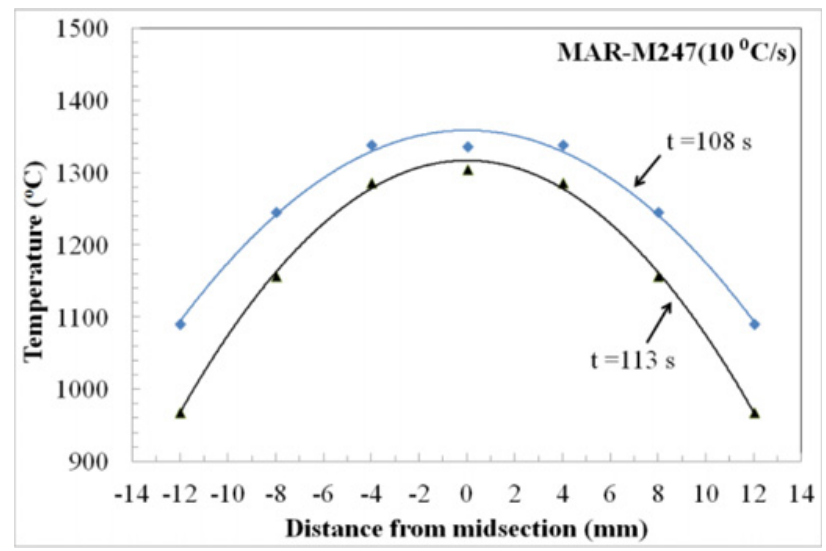

(b)

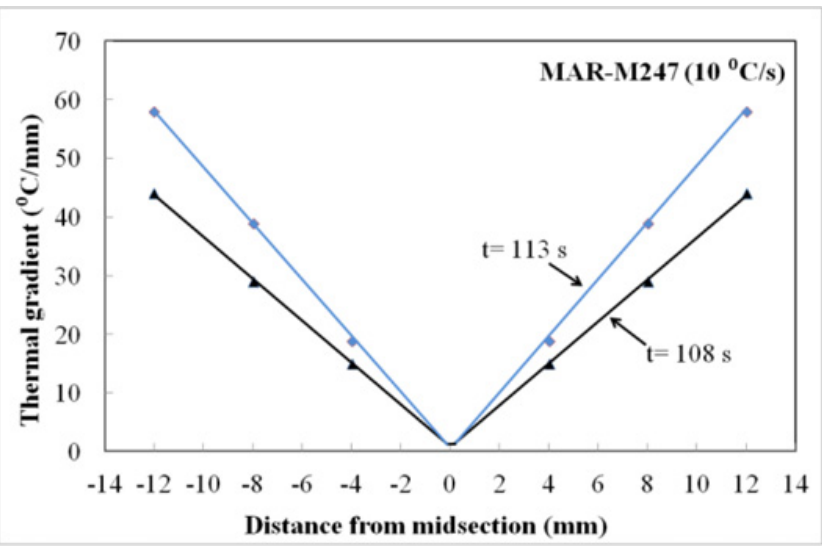

(d)

Figure 3. Temperature distribution in the samples cooled at: a) $0.25^{\circ} \mathrm{C} / \mathrm{s}, \mathrm{b}$ ) $10^{\circ} \mathrm{C} / \mathrm{s}$ and thermal gradient along the axis of the samples cooled at: c) $0.25^{\circ} \mathrm{C} / \mathrm{s}$, d) $10^{\circ} \mathrm{C} / \mathrm{s}$.

Table 2. The constants of T-x equations for various conditions.

\begin{tabular}{|l|l|l|l|l|}
\hline Cooling rate & Time $[\mathrm{s}]$ & \multicolumn{3}{|c|}{ Constants } \\
\cline { 3 - 5 }$\left[{ }^{\circ} \mathrm{C} / \mathrm{s}\right]$ & & $a$ & $b$ & $c$ \\
\hline 0.25 & 94 & -0.2671 & 0 & 1336 \\
\cline { 2 - 5 } & 133 & -0.3917 & 0 & 1326 \\
\hline \multirow{2}{*}{10} & 108 & -1.836 & 0 & 1358 \\
\cline { 2 - 5 } & 113 & -2.422 & 0 & 1316 \\
\hline
\end{tabular}

taken to be $1^{\circ} \mathrm{C} / \mathrm{mm}$ due to the melt convection despite the fact that Eq. (2) yields $G=0^{\circ} \mathrm{C} / \mathrm{mm}$. Considering Figs. $3 c, d$, the variation of thermal gradient with distance shows a linear relationship, where the thermal gradient increases with distance from the midsection. Also in the case of higher cooling rate $\left(10^{\circ} \mathrm{C} / \mathrm{s}\right)$, the thermal gradient increased much faster than in the case of lower cooling rate $\left(0.25^{\circ} \mathrm{C} / \mathrm{s}\right)$. The $\boldsymbol{G}$ - values for the points located at the distance of 4 and $8 \mathrm{~mm}$ from the midsection are listed in Table 1. Results depicted in Fig. 3 clearly show two things. First, the temperature gradient increases linearly from the midsection of the sample toward the cooling extremities and second, the gradient is much steeper in the case of higher cooling rate. It may be observed that the central part of the sample solidified at very low temperature gradients $<1^{\circ} \mathrm{C} / \mathrm{mm}$, whereas the parts at the end of the melting zone, at the distance of $8 \mathrm{~mm}$ from the midsection, were subjected to a temperature gradient as high as $33.6^{\circ} \mathrm{C} / \mathrm{mm}$.

It is well known that the solidification rate $\boldsymbol{V}$ is determined by temperature gradient $\boldsymbol{G}$ and cooling rate $\boldsymbol{R}$. It can be calculated as [14]

$$
V=R / G \text {. }
$$




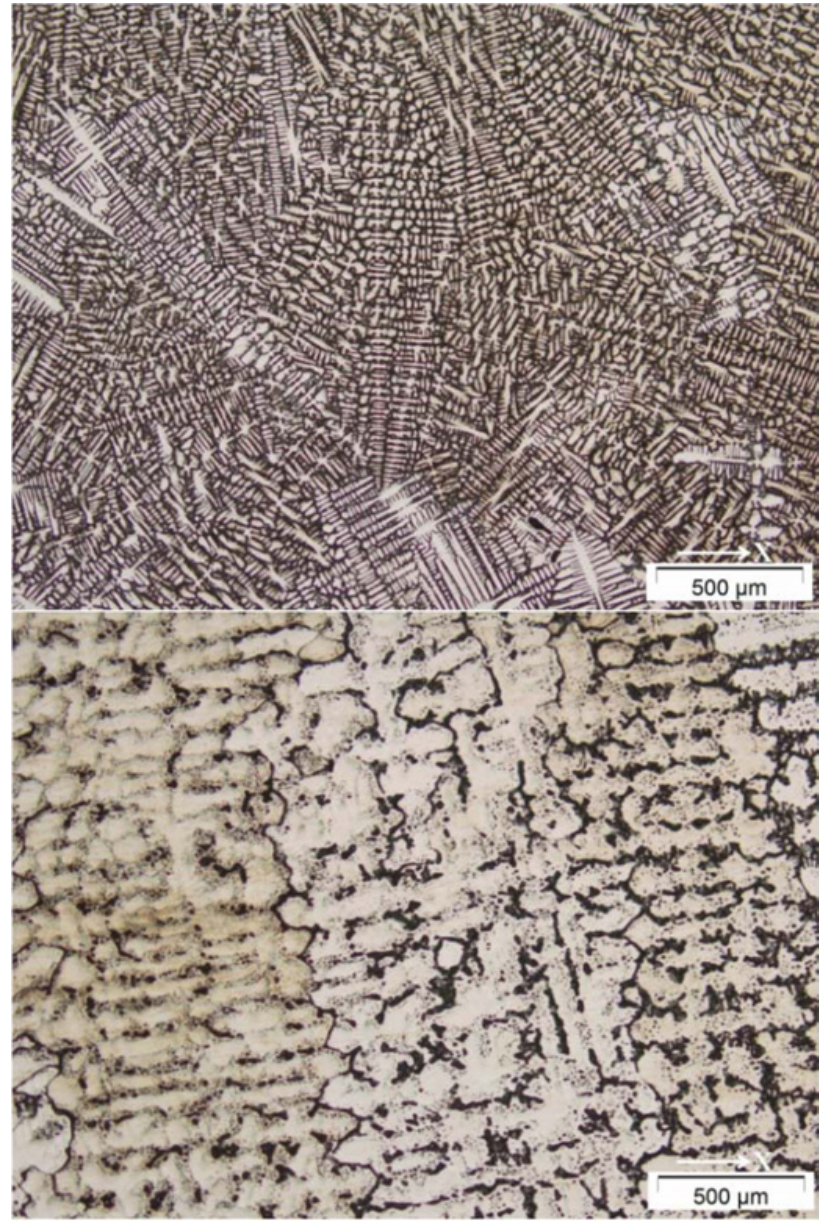

Figure 4. The dendritic microstructure of MAR-M247 at cooling rate $10^{\circ} \mathrm{C} / \mathrm{s}$ at (a) midsection and (b) at $4 \mathrm{~mm}$ distance from the midsection.

The $\boldsymbol{V}$-values were estimated for each studied area along the specimen axis and the data are provided in Table 1. It has been shown that cooling rate and thermal gradient increase with the distance from the midsection. However, the solidification rate follows an opposite trend, as the difference of solidification rates between midsection and $4 \mathrm{~mm}$ from midsection were $9010 \mu \mathrm{m} / \mathrm{s}$ and $167 \mu \mathrm{m} / \mathrm{s}$ for samples cooled at $10^{\circ} \mathrm{C} / \mathrm{s}$ and $0.25^{\circ} \mathrm{C} / \mathrm{s}$, respectively.

The variation of microstructure with distance from the midsection is depicted in Fig. 4. It is found that SDAS increases with the distance from the midsection. For example, the SDAS increases from $19.4 \mu \mathrm{m}$ (Fig. 4a) in the midsection of the sample cooled at $10^{\circ} \mathrm{C} / \mathrm{s}$ to $60.9 \mu \mathrm{m}$ at the distance of $4 \mathrm{~mm}$ from the midsection (Fig. 4b).

A significant body of research has focused on the relationship between solidification parameters and dendritic structure in Ni-based superalloys and suggests that SDAS decreases with increasing cooling rate according to the Kurz-Fisher model,

$$
\lambda_{2}=A * R^{-1 / 3}
$$

where $\lambda_{2}$ is SDAS, $\boldsymbol{R}$ cooling rate and $\boldsymbol{A}$ a constant [14]. Secondary dendrite arm spacing is a key microstructural feature of castings since it influences many of the
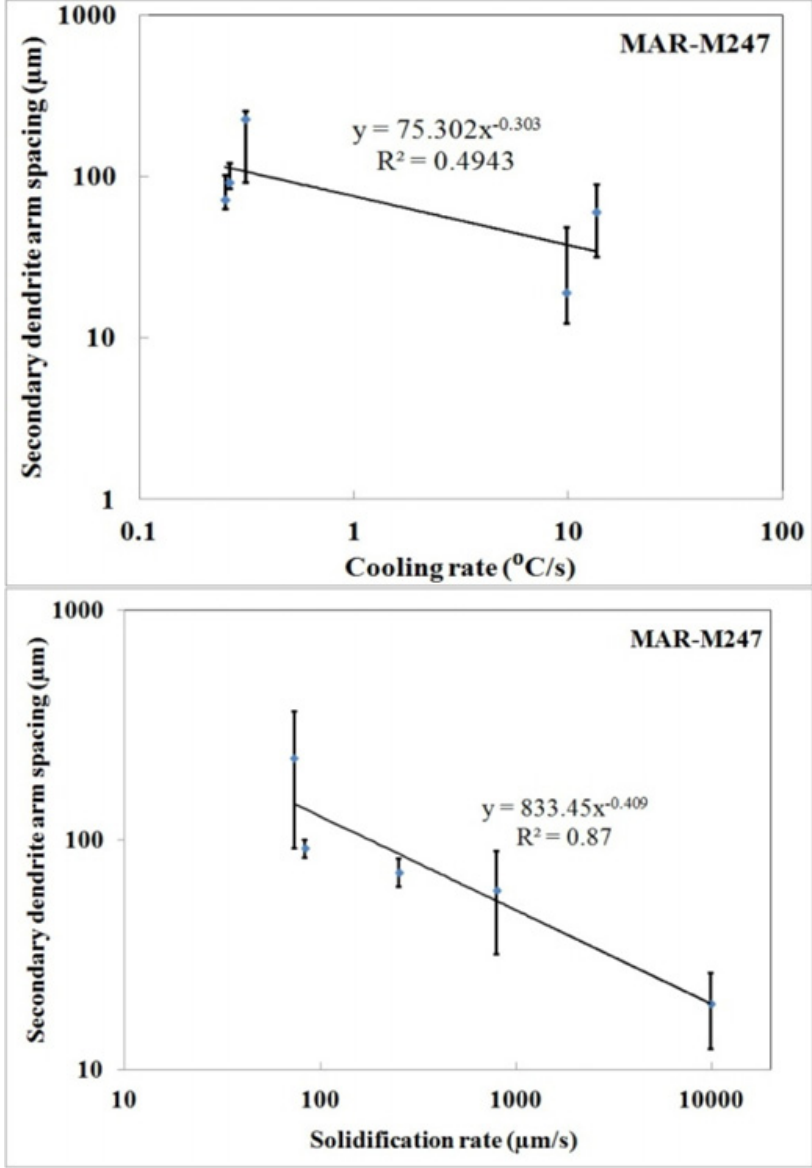

Figure 5. The variation of secondary dendrite arm spacing with: a) cooling rate, b) solidification rate.

important mechanical properties. The reduction of SDAS can be explained by two reasons: first, an increase in the cooling rate cause the reduction of diffusion time which affects solute distribution [15]. Secondly, a higher temperature gradient and cooling rate shorten the length of the solid-liquid phase zone, so that solidification time decreases and consequently solidification rate increases $[15,16]$. Moreover, the coarsening time of secondary dendrite arm spacing is shortened at higher cooling rate, so finer secondary dendrite arm spacing is obtained [17]. In Fig. 5a, the measured SDAS-values are plotted vs. true cooling rate (Table 2).

The regression analysis of these data leads to the trendline equation:

$$
\lambda_{2}=75.30 * R^{-0.303}
$$

which is in accordance with the reported earlier relationship (Eq. (4)) [14]. However, a significant deviation of the experimental points from the trendline is clearly seen (Fig. 5a) resulting in a low value of correlation coefficient $\left(R^{2}=0.49\right)$. This deviation can be rationalized based on the significant variation of the thermal gradient along the axis of samples solidified at both cooling rates (Table 1) in contrast to the earlier investigations [1,6-8] which were carried out at the constant thermal gradient. Therefore, the effect of thermal gradient on the SDAS 
should not be ignored in our analysis. Fig. 5b illustrates the SDAS-values plotted vs. solidification rate which takes into account both cooling rate and thermal gradient (see Eq. (3)).

It is seen that the SDAS-values decrease with increasing solidification rate. Similar results were also reported in the earlier works $[1,5-8,16-20]$. The trendline equation:

$$
\lambda_{2}=833.5_{*} V^{-0.41}
$$

is derived from the regression analysis of these data (Fig. 5b). It should be noted that the deviation of the experimental results from the trendline is much lower $\left(\mathrm{R}^{2}=0.87\right)$ compared to that observed in Fig. 5a. The Eq. (6) is relevant in some extent to the models developed to relate PDAS and solidification parameters, where PDAS is presented as a function of both solidification rate and temperature gradient [5]. It should be also noted that the SDAS was found to be proportional to $V^{-1 / 3}$ in the directionally solidified DD3 Ni-based superalloy [2].

\section{Summary}

The effect of solidification parameters on the secondary dendrite arm spacing in a cast Ni-based superalloy has been studied by a novel approach, based on a physical simulation of melting/solidification experiments with a constant cooling rate and variable temperature gradient. It proved to be effective as in a single sample subjected to a constant cooling rate, but varying temperature gradient, a range of solidification rates were obtained. This in turn enabled obtaining a spread of microstructures corresponding to a range of well controlled solidification rates which were produced in a single melting/solidification experiment. Considering that the Gleeble thermo-mechanical simulator can produce cooling rates as high as $10000^{\circ} \mathrm{C} / \mathrm{s}$, it is clear that a wide range of solidification rates and temperature gradients may be easily reproduced. Therefore, the presented method has a lot of advantageous features that makes it unique. First of all, it may be applied to virtually all metallic materials. Also, it is quite simple and not time consuming. In addition, it can be used for microstructure screening and optimizing relevant solidification processes, from directional solidification, to investment casting and rapid solidification.

The obtained results indicate that the SDAS values do not obey the simple relationship taking into account only cooling rate if there are significant variations of other thermal parameters (local thermal gradient and, therefore, local solidification rate) during the solidification process. In fact, the thermal gradient can be a very important factor affecting SDAS in the investment casting process. Therefore, the local solidification rate can act as a better parameter to relate SDAS and solidification parameters in this case. This finding can be very important for investment casting where dramatic variations of the thermal parameters during solidification can occur, due to the complex shape of the cast products.

This investigation was supported by the project VANCAST (EU, FP7, ERA-NET MATERA +). IS and SM acknowledge gratefully Spanish Ministry of Economy and Competitiveness for funding through the Ramon y Cajal fellowships.

\section{References}

[1] H.S. Whitesell, R.A. Overfelt, Mater. Sci. Eng. A. 318, 264 (2001)

[2] G. Sifeng, L. Lin, X. Yiku, Y. Chubin, Z. Jun, F. Hengzhi, Res. \& Devel. 9, 159 (2012)

[3] X. Xue, L. Xu, Mater. Sci. Eng. A. 499, 69 (2009)

[4] J. Chen, J.H. Lee, C.Y. Jo, S.J. Choe, Y.T. Lee, Mater. Sci. Eng. A. 247, 113 (1998)

[5] H.S. Whitesell, L. Li, R.A. Overfelt, Metall. Mater. Trans. B. 31, 546 (2000)

[6] S. Kostić, A. Golubović, A. Valčić, J. Serb. Chem. Soc. 74, 61 (2009)

[7] J. Zhang, J. Li, T. Jin, X. Sun, Z. Hu, J. Mater. Sci. Technol. 26, 889 (2010)

[8] C. Liu, J. Shen, J. Zhang, L. Lou, J. Mater. Sci. Technol. 26, 306 (2010)

[9] M. J. Donachie, S. J. Donachie, Superalloys: A Technical Guide (ASM International, Ohio, USA, 2002)

[10] S. Milenkovic, I. Sabirov, J. LLorca, Mater. Lett. 73, $216(2012)$

[11] S. Milenkovic, M. Rahimian, I. Sabirov, Metall. Mater. Trans. B. In Press, Available online DOI: 10.1007/s11663-013-9846-4

[12] ASM ready reference. Thermal properties of metals, First printing, (ASM International, USA, 2002)

[13] Gleeble Users Training 2010, Gleeble Systems and Applications, (Dynamic Systems Inc., New York, 2010)

[14] W. Kurz, D. J. Fisher, Fundamentals of Solidification, $4^{\text {th }}$ Revised Edition (Trans. Tech. Publications Inc., Switzerland, 1998)

[15] W. Zhang, L. Liu, X. Zhao, T. Huang, Z. Yu, M. Qu, H. Fu, Rare Met. 28, 633 (2009)

[16] Z. Hu and H. Wang, J. Mater. Sci. Technol. 9, 25 (1993)

[17] Y. Zhang, B. Huang, J. Li, Metall. Mater. Trans. A. 44, 1641 (2013)

[18] B.C. Wilson, E.R. Cutler, G.E. Fuchs, Mater. Sci. Eng. A. 479, 356 (2008)

[19] G. Liu, L. Liu, C. Ai, B. Ge, J. Zhang, H. Fu, J. Alloys Comp. 509, 5866 (2011)

[20] M.M. Franke, R.M. Hilbinger, C.H. Konrad, U. Glatzel, R.F. Singer, Metall. Mater. Trans. A. 42, 1847 (2011) 